\title{
Organisational context and behavioural complexity affecting ambidextrous behaviours among SMEs
}

\author{
Wai Chuen Poon \\ Sunway University Business School, Sunway University, Petaling Jaya, Malaysia, and \\ Osman Mohamad \\ Faculty of Management, Multimedia University - Cyberjaya Campus, Cyberjaya, \\ Malaysia
}

\begin{abstract}
Purpose - The purpose of this paper is to examine the antecedents of exploitative and explorative behaviours and to give valuable insight into the role of ambidextrous behaviours in developing creativity and innovativeness among owner-managers in SMEs.

Design/methodology/approach - A review of existing literature was carried out and drawing upon ownermanagers, a survey using structured questionnaires was carried out with a total of 183 useful responses received. The proposed model was analysed using SmartPLS v2.3.7.

Findings - The empirical result suggests that behavioural complexity and organisational flexibility encourages exploitative and explorative behaviours, while ambidextrous behaviours encourage creativity and innovativeness. Rigidity, on the other hand, hinders the cultivation of ambidextrous behaviours.

Originality/value - The paper entails useful implication by demonstrating that flexibility enables ownermanagers to reconcile competing demands and consequently, cultivate innovative outcomes. In this regard, business owner-managers must learn implicitly how to juggle these contradictory demands, suggesting an internal balancing mechanism independent of the organisational context and individual behavioural complexity. This paper suggests that cultivation of exploitative and explorative behaviours among ownermanagers is useful in encouraging ambidextrous behaviours among SMEs.
\end{abstract}

Keywords Small and medium enterprises (SMEs), Ambidextrous behaviours, Entrepreneurial characteristics, Organisational context, Behavioural complexity, Malaysia

Paper type Research paper

\section{Introduction}

Small and medium enterprises (SMEs) are viewed as the leading contributors for the longterm development of many nations' economy. In Malaysia, SMEs account for more than 90 per cent of business establishments (SME Corporation Malaysia, 2016) and contribute to sustaining and strengthening of domestic economy, promoting growth in the private sector, continuous innovation, providing employment to the nation, adoption of new technology (e.g. green technology) and as a source of revenue for the government (Hazlina et al., 2010). Unfortunately, Malaysian SMEs have a failure rate of 42-50 per cent as recorded between 2005 and 2012 (SME Corporation Malaysia, 2012). These SMEs often have limited resources to meet the demands of rapidly changing consumers' preferences, governmental change coupled with foreign and domestic competition. Overcoming these challenges creatively and innovatively remains pivotal towards the continual survival of SMEs in Malaysia.

Ambidextrous behaviours (ABs) have been highlighted as a critical component which allows firms to manage these challenges (e.g. Gibson and Birkinshaw, 2004; Lubatkin et al., 2006). ABs refer to the extent to which individuals engage in and switch between explorative behaviours and exploitative behaviours in their daily task (Mom et al., 2009). Accordingly, exploitative behaviours refer to the behaviours that involve refining existing assets,
Ambidextrous behaviours among SMEs

Received 25 March 2019 Revised 17 July 2019 25 October 2019 Accepted 11 November 2019 
competencies and knowledge, while explorative behaviour relates to the behaviours to gain more knowledge and to take on new or alternative opportunities (Benner and Tushman, 2003; Gupta et al., 2006; Jansen et al., 2008). However, it can be incredibly difficult for an individual to be ambidextrous (Gupta et al., 2006) due to the contradictive nature of explorative and exploitative behaviours that call for different mind-sets (Mom et al., 2009; Simsek et al., 2009). Individuals are required to consciously alternate between explorative and exploitative behaviours.

A majority of studies have heavily emphasised the macro-level needs to address these contradictions to be ambidextrous. However, there is a lack of understanding on ambidextrous, explorative and exploitative behaviours and their impact at the micro level. As a result, most studies have ignored individual's ability to deal with contradictory demands (Raisch et al., 2009; Mom et al., 2009; Kauppila and Tempelaar, 2016; Popadić and Črne, 2016). Based on this argument, this paper investigates the factors influencing ambidextrous, exploitative and explorative behaviours. In this regard, it is believed that the mechanism mitigating the development of ambidextrous behaviours would improve the understanding of how individuals attain $\mathrm{AB}$. Furthermore, through the attainment of $\mathrm{AB}$, firms are in a better position to grapple with future challenges.

Based on these research gaps, this study contributes to the emergent conversation on $\mathrm{AB}$ in two ways; first, the present study examines the antecedent of $\mathrm{AB}$. From a micro level, an individual's ability to manage such contradiction would greatly influence the firm's performance (Kauppila and Tempelaar, 2016). Hence, this study is grounded on the perspective that organisational context $(\mathrm{OC})$ and individual behavioural complexity $(\mathrm{BC})$ influence the achievement of $\mathrm{AB}$. Second, this study explores the influences of $\mathrm{AB}$ on creative and innovative capability; according to O'Reilly and Tushman (2013), firm-level ambidexterity is positively associated with the increase in firm innovation. Agreeing with the theory of dynamic capabilities, this paper also examines whether AB affects individual creativity and innovativeness. Consequently, this study will ultimately provide owner-managers a low-cost opportunity to improve competitive advantages in SMEs.

\section{Review of literature}

Ambidextrous behaviours $(A B)$. The need for an organisation to accommodate, explore and exploit was first mentioned by Robert Duncan (1976 as cited in O'Reilly and Tushman, 2013), who argues that there is a need for a different mind-set in the execution of innovation activities. Larger organisations are usually able to clearly define specific tasks to either explore or exploit in each functional department. However, smaller organisations are often resource challenged which hinders these organisations to clearly define specific task. Hence, it falls upon the individual members in SMEs to develop methods and new approaches to undertake contradictive behaviours. Thus, individuals must perform both explorative and exploitative behaviours to be considered ambidextrous. Scholars have argued that explorative and exploitative behaviours are not only distinct dimensions but are also mutually enabling (Farjoun, 2010); therefore, focusing only on either explorative or exploitative behaviours is maladaptive and would not allow the individuals to identify complementarities between opposing behaviours (Miron-Spektor et al., 2011).

Ambidextrous behaviours are possible at the individual level (Adler et al., 1999; MironSpektor et al., 2011), and such behaviours are necessary for firms to achieve a higher standard of performance (Kauppila and Tempelaar, 2016). The attainment of AB is highly desired as such behaviours positively impact performance, firm survivability (e.g. O'Reilly and Tushman, 2013) and entrepreneurial characteristics (e.g. Poon et al., 2018a); however, due the paradoxical demands, individual faces an uphill challenge in achieving $\mathrm{AB}$. The nurturing of $\mathrm{AB}$ demands conflicting organisational structures and a different set of attitudes due to the 
paradoxical demands and challenges it imposed upon individuals and the organisations (Tushman and O'Reilly, 1996).

Kauppila and Tempelaar (2016) argue that AB could be enhanced through organisational factors. Meanwhile, Raisch et al. (2009) added that instead of assuming that ABs are determined by organisational factors, both exploitative and explorative behaviours are heavily influenced by individual characteristics. This perspective is in line with research done on work design, which has argued that in contemporary jobs, employees at all levels tend to have a considerable amount of discretion within their environment to act proactively and take on a wider and broader work role (Ilies et al., 2005). It was also argued that employees are increasingly expected to take self-directed action to anticipate or initiate changes in their work roles (Griffin2007).

On the other hand, while the pursuit of achieving $\mathrm{AB}$ is particularly challenging for SMEs that lack resources, capabilities and experience to pursue explorative and exploitative behaviours simultaneously (Voss and Voss, 2013), it is still vital for SMEs to attain ambidexterity with equal vigour and determination (Smith et al., 2012). From the perspective of dynamic capability, one of the most valuable resources to an organisation are the individual members. These resources are crucial to the development of firm's capabilities and the reconfiguration of firm's capability in response to the dynamic business environment which will improve the overall business performance. $\mathrm{AB}$ serves as a capability that drives the firm forward encouraging sustainable competitive advantages, such as creativity and innovativeness, which are the recipe for continuous innovation within an organisation.

Creativity and innovativeness. Creativity refers to the process of generating novel and useful ideas (Sarooghi et al., 2015) and the ability to produce something new through imaginative skill. Through the generation of new ideas or processes, new solution to an existing problem, new methods or product or services are developed. As such, the creation of new products, services, or business processes begins with an individual or a group of people creating a good idea and developing that idea beyond its initial stage (Baer, 2012). The theory of creativity argues that individuals' creativity is the integration of psychological and social components, while concurrently being heavily influenced by their perceived work environment (Amabile, 2013). Sarooghi et al. (2015) stated that creativity is challenged at all levels in an organisation and is greatly affected by organisational, environmental and cultural factors.

Similarly, studies on creativity and innovation suggest that although organisational elements may either support or inhibit creative activities in organisations, employees' creative behaviour primarily depends on their characteristics, such as their personality and motivational processes (Amabile, 2013). In this regard, encouragement of creative and innovative effort is vital at all levels as it develops key competitive strength and entrepreneurial characteristics. Innovativeness is the propensity to engage in and support new ideas, novelty, experimentation and the creative process (Gupta and Sebastian, 2017). Innovativeness is the tendency of an individual to participate in creative processes and experimentation through the introduction of new products or services (Rauch et al., 2009). Innovativeness includes the propensity and the willingness to promote and support novel ideas, experimentation and creative processes that may lead to new products. Organisational support spurs employees to undertake more innovative and creative roles and suggest improvement within the organisation itself.

Drucker (2014) argued that creativity and innovativeness are the principal ingredients for companies to compete and survive. Knowledge is considered a precursor to creative actions where entrepreneurs draw upon knowledge which is essential to performing creative processes that lead to the generation of new ideas (Shane, 2000). Knowledge leads back to the central theme of March's (1991) argument about organisational learning. It can be argued that $\mathrm{AB}$ causes an individual to continuously learn through exploitative and explorative 
behaviours and as a result, enhances creativity and innovativeness. Miron-Spektor et al. (2011) supported this line of argument, by arguing that a paradoxical frame (e.g. sense of conflict and integrative complexity) sparks individual creativity. Paradoxical frames elicit an implicit or explicit sense of conflict and enhance complex thinking among individuals (Sarooghi et al., 2015). As such, the ability to reconcile differences encourages individuals to use a broad and flexible method to incorporate information and ability to break out of the norm (Amabile, 2013), thus influencing individual creativity and innovativeness (Poon et al., 2018b). From the perspective of dynamic capability, an individual's creativity and innovativeness are viewed as a sustainable competitive advantage and a unique critical asset for SMEs. For this reason, the following hypotheses were generated:

H1. AB has a positive impact on creativity.

H2. $\mathrm{AB}$ has a positive impact on innovativeness.

Organisational context $(O C)$ - $A B$ relationship

Gibson and Birkinshaw (2004) defined OC as a system, processes and a set of beliefs that shape individual-level behaviours in an organisation. Ghosal and Bartlett (1994) proposed that OC consists of four elements. The first element, "discipline" encourages members to step up to strive in meeting the expectation that was created by their explicit or implicit commitments. The second element is "stretch" which is an aspect that activates members to step up for more ambitious goals or objective as to settle for lesser goals. Members are more likely to stretch through having a shared ambition, collective identity and personal meaning to the firm. The third element "support" is an aspect that encourages firm members to help one another and provide countenance to others. The final component "trust" is an aspect that allows members to depend on one another based on commitment towards one. In an organisation, Gibson and Birkinshaw (2004) proposed that members would need to be disciplined and stretch to achieve the ambitious objective, while at the same time, they would need support and trust to reach the objective, in return forming a mutually cooperative environment for members or the organisation, which appears like a balance between the pair of hard elements (discipline and stretch) with the pair of elastic elements (support and trust).

Creating a balance between discipline, stretch, support and trust would encourage members at the individual level, to initiate, cooperate and learn together with one another. However, this would all depend on their willingness to do so (Ghoshal and Bartlett, 1994). OC does not force individual members to perform a certain action, but rather it creates a supportive working environment for members of the organisation to do "anything" to achieve desired results. However, while OC is important, flexibility does not lie with the system, rather it comes with behavioural choices regarding human resources to meet different organisational goals (Wright and Snell, 1998). Gibson and Birkinshaw (2004) extended the initial framework by studying the condition where a supportive environment in an organisation is achieved. The findings indicate that members can engage in both exploitation and exploration activities that will result in innovation ambidexterity leading to an increase in performance for large organisations. Due to the limitation of resources and a small group of individuals making virtually all the strategic decisions in SMEs (Heavey et al., 2015), such composition of organisational ecology will be different as compared to the larger organisation. In a smaller firm, strong ties among members will create a trusting and psychologically safe setting which could encourage owner-managers, who would otherwise remain passive to innovate. In addition, the depth, breadth and efficiency of knowledge exchanges among the members could increase through close social interaction among all members of the organisation which will (Lane and Lubatkin, 1998) facilitate explorative and exploitative behaviours. Based on this logic, the following hypothesis regarding the relationship between $\mathrm{OC}$ and $\mathrm{AB}$ was formulated: 
H3. OC has a positive impact on explorative behaviours.

Ambidextrous

H4. OC has a positive impact on exploitative behaviours. behaviours

H5. $\mathrm{OC}$ has a positive impact on $\mathrm{AB}$. among SMEs

\section{Behavioural complexity $(B C)-A B$ relationship}

The logic underlying $\mathrm{BC}$ could be traced back to the competing values framework (or CVF, Quinn and Rohrbaugh, 1983). Denison et al. (1995, p. 526) explained BC as the ability of someone who can "perform the multiple roles and behaviours that circumscribe the requisite variety implied by an organisational or environmental context". The concept of $\mathrm{BC}$ could be used to explain the concept of cognitive complexity (Rosing et al., 2011), where complexity refers to the capability of the individual to respond to a host of puzzling and opposing forces which even includes the concurrent existence of opposing forces.

$\mathrm{BC}$ framework is defined by two dichotomous or competing values, Flexible versus Stable Structure and Internal versus External Focus, along with four quadrants comprising of orthogonal factors, specifically compete, control, collaborate and create roles (as shown in Figure 1) (Lawrence et al., 2009). In this light, compete behavioural roles refer to planning, goal setting and productivity; collaborate behavioural roles refer to cohesion, morale and training; while control behavioural roles refer to information management, stability and control; and finally create behavioural roles refer to adaptation and growth (Lawrence et al., 2009). Theoretically, each quadrant is distinct from the others; however, the quadrant retains a specific spatial relationship with the quadrants sharing the same dimensions (Denison et al., 1995).

The greater the adaptability of individuals in carrying out the four behavioural roles would allow them to be better positioned to address organisational demands (Denison et al., 1995). As the environment changes, the greater the adaptability of individuals in carrying out the four behavioural roles would allow them to be better positioned to address organisational demands (Hooijberg and Quinn, 1992). BC demands individuals to be both loose and strict, creative and routine and formal and informal at the same time (Poon et al., 2018a). Weick (2003) stated that the leader who can combine opposing roles possesses greater adaptability to shifting demands. In a complex situation, a specific combination of behaviours, skills and roles will be best suited to react to a complicated, puzzling and undefined problem in the organisation or environmental context. Smith et al. (2012) argued that entrepreneurs constantly need to juggle between contradictory demands, accept, differentiate and integrate to move beyond the formal rationalist mental models which cause their behavioural roles to shift seamlessly. Individuals in an organisation play a crucial role in finding a balance between this set of behaviours because it is crucial to prevent obsolescence. Based on the earlier arguments, three hypotheses were generated as follows:

\begin{tabular}{|c|c|c|c|}
\hline & \multicolumn{2}{|c|}{ Focus Dimension } \\
\hline & & Internal Structure & External Structure \\
\hline \multirow{2}{*}{ 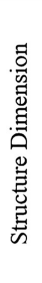 } & $\begin{array}{c}\text { Flexible } \\
\text { Structure }\end{array}$ & $\begin{array}{l}\text { Collaborate Roles } \\
\text { - } \quad \text { Encouraging Participation } \\
\text { - } \quad \text { Showing Concern } \\
\text { - } \quad \text { Developing People }\end{array}$ & $\begin{array}{l}\text { Create Roles } \\
\text { - Initiating Significant Change } \\
\text { - } \quad \text { Anticipating Customer Needs } \\
\text { - Inspiring People to Exceed } \\
\quad \text { Expectation }\end{array}$ \\
\hline & $\begin{array}{c}\text { Stable } \\
\text { Structure }\end{array}$ & $\begin{array}{l}\text { Control Roles } \\
\text { - } \quad \text { Expecting Accurate Work } \\
\text { - } \quad \text { Controlling Projects } \\
-\quad \text { Clarifying Policies }\end{array}$ & $\begin{array}{l}\text { Compete Roles } \\
-\quad \text { Modelling A Hard Work Ethic } \\
-\quad \text { Focusing on the Competition } \\
-\quad \text { Emphasising Speed }\end{array}$ \\
\hline
\end{tabular}

Figure 1. Behavioural roles (Lawrence et al., 2009) 
H6. $\mathrm{BC}$ has a positive impact on explorative behaviours.

H7. $\mathrm{BC}$ has a positive impact on exploitative behaviours.

H8. $\mathrm{BC}$ has a positive impact on $\mathrm{AB}$.

\section{Methods}

Participants and procedure

Kline (2005) recommended power analysis to estimate the minimum samples size by using G*Power 3.1 program (Faul et al., 2007) commonly used in social or behavioural studies. According to $\mathrm{G}^{*}$ Power, the minimum estimate sample size would be 160 respondents with the power at 95 per cent, the alpha at 0.05 with the medium effect size of 0.15 and 8 number of predictors. Based on past studies, this study adopted a conservative estimate for the response rate of only around 15-20 per cent among Malaysian SMEs (Arham et al., 2014). The present study drew upon a list of companies obtained from the SME Corporation. The list consists of 11,084 SMEs in Kuala Lumpur and Selangor, which represent 35.5 per cent of SMEs in Malaysia (SME Corporation Malaysia, 2016). Data collection was carried out between December 2015 and April 2016 from a randomised sample list of 1000 SPSS cases. Out of the 1,000 cases, only 220 owner-managers were emailed with a self-administered online questionnaire after they have expressed willingness to take part in the survey. Due to the relatively flat structure in SMEs, owner-managers are significantly involved in day-to-day operation, making them a prime source of information. All respondents were assured of their confidentiality and given two to four weeks to complete the survey. The responses of 183 owners-managers were collected for this study.

Since the survey was self-administered and some respondents need longer time to complete the survey, a statistical remedial method was needed to determine whether there is no significant difference between early and late respondents and that non-response bias will not affect the result of the study (Knight and Cavusgil, 2004). Thus, T-test was conducted on the two different groups (i.e. early respondent and late respondent) to examine if any significant differences that exist between them (Coakes et al., 2010). Respondents that failed to complete the survey within the allocated time were given reminders and were given an additional two weeks to complete the survey. These respondents are considered as late respondents. Levene's test indicated a probability of $0.626(p>0.05)$, thus, indicating the null hypotheses signifying that there is no response bias. To better understand the characteristics of respondents, a summary of the frequency distribution method is presented in Table I.

\begin{tabular}{llr}
\hline Profile & & \\
\hline Gender & Male & $118(64.50 \%)$ \\
& Female & $65(35.50 \%)$ \\
Ethnicity & Malay & $20(10.90 \%)$ \\
& Chinese & $144(78.70 \%)$ \\
& Indian & $12(6.60 \%)$ \\
Types of Industry & Indigenous & $7(3.80 \%)$ \\
& Service & $148(80.90 \%)$ \\
& Manufacturing & $13(7.10 \%)$ \\
Position & Others (Agriculture, Construction, Mining and Quarrying) & $22(12.00 \%)$ \\
& Owner & $73(39.90 \%)$ \\
& Manager & $110(60.10 \%)$
\end{tabular}

Table I.

Demographic profile of Position respondent and SMEs 


\section{Measures}

Ghoshal and Bartlett (1994) conceptualised OC into four attributes (i.e. discipline, stretch, support and trust) as interdependent attributes. According to Gibson and Birkinshaw (2004), $\mathrm{OC}$ is measured by developing a multi-item scale to represent the dimensions of discipline, stretch, support and trust as identified by Ghoshal and Bartlett (1994). However, Gibson and Birkinshaw (2004) reported that all of the four interdependent attributes could not be identified separately through factor analysis as only two factors were identified: (1) performance management context $(\alpha=0.89)$ and (2) social context ( $\alpha=0.93)$. Thus, estimating $\mathrm{OC}$, this present study adopts the multiplicative interaction between performance management context and social context by Gibson and Birkinshaw (2004) to reflect the argument that it should be considered holistically.

Behavioural complexity captures the range of behaviours that a person can perform (Hooijberg et al., 1997). The present study adopted Lawrence's et al. (2009) instrument, which consists of 36 items that capture the essence of $\mathrm{BC}$ through third-order formative construct repeated indicator approach. The present study believes that owner-managers exhibit some evidence the four behavioural roles (i.e. Collaborate, Create, Compete and Control) in BC. Lawrence et al. (2009) recorded an average internal consistency of 0.82 and ranged from 0.71 to 0.93 for all four quadrants. Furthermore, this study employs scale developed by Lubatkin et al. (2006) which consists of 12 items measuring exploitative behaviours $(\alpha=0.83)$ and explorative behaviours $(\alpha=0.84)$ to capture the essence of $\mathrm{AB}$. AB is also conceptualised using a second-order formative construct with repeated indicator reflecting the nature of ambidexterity. As for creativity ( $\alpha=0.86)$, six items from Jia et al. (2014) and three items from Covin and Slevin (1989) measure innovativeness $(\alpha=0.86)$. All variables were measured using a seven-point Likert scale.

\section{Data analysis}

Common method variance (CMV) is vital to examine the presence of method bias particularly in this study as the data is obtained from a single data source. The unrotated factor analysis using the eigenvalue greater than 1 criterion revealed that 14 distinct factors accounted for 73.43 per cent of the variance. The first factor captured is only 29.56 per cent of the total variance in the whole data. According to Podsakoff and Organ (1986), if a single latent construct accounts for the majority ( $>50$ per cent) of the explained variance, $\mathrm{CMV}$ is pervasive and problematic. In this light, method bias exists in the data set if a percent variance explained of the first factor is more than 50 per cent. Hence, based on Exploratory Factor Analysis (EFA), since the first factor did not account for most of the variance, the study concludes that CMV was not serious and unlikely to affect the findings of this study. Structural equation modelling (SEM) technique was used for the analysis of the proposed framework. The data were tested using partial least squares (PLS) approach with Smart PLS v3.2.7.

\section{Assessment of measurement (outer) model}

Following the two-stage analytical procedures by Gerbing and Anderson (1988), the validity and goodness of the measurement model were first tested. The evaluation of convergent validity was determined based on the item loadings, composite reliability (CR) and average variance extracted (AVE). CR which depicts the degree to which the construct indicators indicate the latent construct ranged from 0.806 to 0.922 exceeding the recommended level of 0.7 which was suggested by Hair et al. (2017). In this study, it was found that almost all of the item loadings are above 0.5 ; hence, as suggested by Hair et al. (2017), for loading values lower than 0.5, specifically items EX10 and EX12 were deleted from this study. As for AVE, Hair et al. (2017) posited that if the value is 0.5 and higher, this represents a sufficient degree of convergent validity, while the value below 0.5 represents otherwise. Table II depicts the summary of items, loadings, AVE, CR for the first-order construct.
Ambidextrous behaviours among SMEs 
IJOTB

\begin{tabular}{|c|c|c|c|c|}
\hline $\begin{array}{l}\text { First-order construct } \\
\text { Organisational context (OC) }\end{array}$ & $\begin{array}{l}\text { Items } \\
\text { OC }\end{array}$ & $\begin{array}{l}\text { Loadings } \\
\text { SIC }\end{array}$ & $\begin{array}{l}\text { AVE } \\
\text { SIC }\end{array}$ & $\begin{array}{l}\mathrm{CR} \\
\mathrm{SIC}\end{array}$ \\
\hline \multirow[t]{3}{*}{ Encouraging participation } & $\mathrm{BCl}$ & 0.868 & \multirow[t]{3}{*}{0.769} & \multirow[t]{3}{*}{0.909} \\
\hline & $\mathrm{BC} 2$ & 0.857 & & \\
\hline & $\mathrm{BC} 3$ & 0.905 & & \\
\hline \multirow[t]{3}{*}{ Developing people } & $\mathrm{BC} 4$ & 0.828 & \multirow[t]{3}{*}{0.723} & \multirow[t]{3}{*}{0.886} \\
\hline & BC5 & 0.881 & & \\
\hline & $\mathrm{BC} 6$ & 0.840 & & \\
\hline \multirow[t]{3}{*}{ Acknowledging people's needs } & $\mathrm{BC} 7$ & 0.890 & \multirow[t]{3}{*}{0.789} & \multirow[t]{3}{*}{0.918} \\
\hline & $\mathrm{BC} 8$ & 0.882 & & \\
\hline & BC9 & 0.891 & & \\
\hline \multirow[t]{3}{*}{ Anticipating customer's needs } & $\mathrm{BC} 10$ & 0.857 & \multirow[t]{3}{*}{0.683} & \multirow[t]{3}{*}{0.866} \\
\hline & BC11 & 0.821 & & \\
\hline & BC12 & 0.801 & & \\
\hline \multirow[t]{3}{*}{ Initiating significant change } & $\mathrm{BC} 13$ & 0.798 & \multirow[t]{3}{*}{0.744} & \multirow[t]{3}{*}{0.897} \\
\hline & $\mathrm{BC} 14$ & 0.920 & & \\
\hline & $\mathrm{BC} 15$ & 0.865 & & \\
\hline \multirow[t]{3}{*}{ Inspiring people to exceed expectations } & $\mathrm{BC} 16$ & 0.867 & \multirow[t]{3}{*}{0.699} & \multirow[t]{3}{*}{0.874} \\
\hline & $\mathrm{BC} 17$ & 0.884 & & \\
\hline & $\mathrm{BC} 18$ & 0.751 & & \\
\hline \multirow[t]{3}{*}{ Clarifying policies } & BC19 & 0.849 & 0.798 & 0.922 \\
\hline & BC20 & 0.922 & & \\
\hline & $\mathrm{BC} 21$ & 0.907 & & \\
\hline Expecting accurate work & $\mathrm{BC} 22$ & 0.880 & 0.737 & 0.894 \\
\hline & $\mathrm{BC} 23$ & 0.847 & & \\
\hline & BC24 & 0.849 & & \\
\hline Controlling projects & $\mathrm{BC} 25$ & 0.668 & 0.596 & 0.815 \\
\hline & BC26 & 0.836 & & \\
\hline & $\mathrm{BC} 27$ & 0.802 & & \\
\hline Focusing on competition & $\mathrm{BC} 28$ & 0.885 & 0.721 & 0.885 \\
\hline & BC29 & 0.901 & & \\
\hline & ВС30 & 0.754 & & \\
\hline Showing a hard work ethic & BC31 & 0.871 & 0.737 & 0.893 \\
\hline & BC32 & 0.886 & & \\
\hline & BC33 & 0.816 & & \\
\hline Emphasising speed & BC34 & 0.837 & 0.725 & 0.888 \\
\hline & BC35 & 0.884 & & \\
\hline & ВC36 & 0.832 & & \\
\hline Creativity & CREA1 & 0.793 & 0.656 & 0.920 \\
\hline & CREA2 & 0.856 & & \\
\hline & CREA3 & 0.827 & & \\
\hline & CREA4 & 0.796 & & \\
\hline & CREA5 & 0.841 & & \\
\hline & CREA6 & 0.743 & & \\
\hline Explorative behaviours & EX1 & 0.837 & 0.600 & 0.899 \\
\hline & EX2 & 0.807 & & \\
\hline & EX3 & 0.729 & & \\
\hline & EX4 & 0.840 & & \\
\hline & EX5 & 0.807 & & \\
\hline & EX6 & 0.598 & & \\
\hline Exploitative behaviours & EX7 & 0.781 & 0.513 & 0.806 \\
\hline & EX8 & 0.563 & & \\
\hline & EX9 & 0.799 & & \\
\hline & EX11 & 0.698 & & \\
\hline Innovativeness & INNO1 & 0.801 & 0.712 & 0.881 \\
\hline & INNO2 & 0.877 & & \\
\hline & INNO3 & 0.851 & & \\
\hline
\end{tabular}

Table II.

Items, loadings, AVE and CR for first-order construct
Note(s): Variance Inflation Factor (VIF), Average Variance Extracted (AVE), Single Indicator Construct (SIC). EX10 and EX12 were dropped due to low loading value 
Subsequently, for second-order and third-order constructs, the guidelines established by Hair et al. (2017) were adopted for the assessment of multicollinearity, weights and significance. Repeated indicator approach was adopted to model the second-order and third-order constructs. Variance inflation factor (VIF) of 0.2 and lower or 5 and higher indicates the presence of multicollinearity (Hair et al., 2017). Since SmartPLS does not assume a normal distribution of data, a bootstrapping procedure was conducted to ascertain the significance of each indicator. $T$-value is clearly above $1.96(\phi<0.05)$. Table III depicts the VIF and outer weights for second-order construct while Table IV depicts the VIF and outer weights for third-order construct.

Henseler et al. (2010) suggested assessing discriminant validity through heterotraitmonotrait ratio (HTMT). HTMT refers to the average of the heterotrait-heteromethod correlations (i.e., the correlations of indicators across constructs measuring different phenomena), which is relative to the average of the monotrait-heteromethod correlations (i.e., the correlations of indicators within the same construct). HTMT could be used to examine discriminant validity. The most conservative criterion, HTMT is used to assess discriminant validity at the cut-off value of 0.85 (Henseler et al., 2010; Voorhees et al., 2016) where a greater value signifies a problem with discriminant validity. Table $\mathrm{V}$ summarises the HTMT analysis while Figure 2 presents the results of the measurement model (see Table VI).

\section{Assessment of structural (inner) model}

To assess the structural model, this study adopted a bootstrapping method of 5,000 resampling procedure to estimate standard errors, path coefficient and t-statistics (Hair et al., 2017). The results depict that $\mathrm{OC}$ and $\mathrm{BC}$ have a positive relationship with both exploitative

\begin{tabular}{llccc}
\hline Second-order construct & First-order construct & Weights & $T$-value & VIF \\
\hline Ambidextrous behaviour (AB) & Explorative behaviours & 0.750 & 9.772 & 2.179 \\
& Exploitative behaviour & 0.347 & 20.040 & 1.917 \\
Collaborate & Encouraging participation & 0.382 & 15.424 & 1.776 \\
& Developing people & 0.402 & 19.367 & 2.107 \\
Create & Acknowledging people's needs & 0.396 & 16.444 & 1.590 \\
& Anticipating customer's needs & 0.360 & 11.383 & 1.346 \\
Control & Initiating significant change & 0.419 & 13.513 & 1.466 \\
& Inspiring people to exceed expectations & 0.459 & 14.410 & 1.732 \\
& Clarifying policies & 0.467 & 13.500 & 1.434 \\
Compete & Expecting accurate work & 0.432 & 6.615 & 1.593 \\
& Controlling projects & 0.320 & 11.364 & 1.562 \\
& Focusing on competition & 0.364 & 10.526 & 1.224 \\
& Showing a hard work ethic & 0.444 & 13.119 & 1.470 \\
& Emphasising speed & 0.454 & 13.748 & 1.543
\end{tabular}

\section{Ambidextrous behaviours among SMEs}

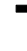


behaviours $(\beta=0.325, t=3.605, p<0.01 ; \beta=0.355, t=3.324, p<0.01)$ and explorative behaviours $(\beta=0.457, t=4.829, p<0.01 ; \beta=0.310, t=3.513$, $p<0.01)$. On the other hand, this study found that $\mathrm{OC}$ and $\mathrm{BC}$ do not have any significant influence on $\mathrm{AB}(\beta=0.002$, $t=0.605, p>0.05 ; \beta=0.001, t=0.159, p>0.05)$ while $\mathrm{AB}$ has a positive relationship with creativity $(\beta=0.473, t=9.151, p<0.01)$ and innovativeness $(\beta=0.375, t=6.566, p<0.01)$. Next, Hair et al. (2017) suggested that in the evaluation of the predictive relevance of the endogenous model, blindfolding procedure was applied. By using omission distance of 7 , the predictive relevance $\left(Q^{2}\right)$ creativity value of 0.123 , innovativeness $Q^{2}$ value of 0.089 , exploitative behaviours $Q^{2}$ value of 0.196 and explorative behaviours $Q^{2}$ value of 0.278 were obtained. In this regard, the model has predictive relevance, since $Q^{2}$ is greater than 0 . Figure 3 presents the results of the structural model (see Figure 4).

\section{Discussions}

The current study investigates the role of $\mathrm{AB}$ on creativity and innovativeness among ownermanager in Malaysian SMEs. The findings showed that the relationship of $\mathrm{AB}$ with creativity and innovativeness was positive and statistically significant. These findings are consistent with the core assumption of ambidexterity (Rosing et al., 2011; O'Reilly and Tushman, 2013). Due to the act of switching between explorative and exploitative behaviours, $A B$ permits owner-managers to be flexible as well as to doing things differently, experiment and seek new

Table V.

Heterotrait-monotrait ratio (HTMT) analysis

\begin{tabular}{lccccr}
\hline & 1 & 2 & 3 & 4 & 5 \\
\hline 1. Ambidextrous behaviours (AB) & & & & & \\
2. Behavioural complexity (BC) & 0.716 & & & & \\
3. Creativity & 0.490 & 0.548 & & \\
4. Innovativeness & 0.429 & 0.370 & 0.767 & 0.499 \\
5. Organisational context (OC) & 0.763 & 0.696 & 0.521 & \\
\hline
\end{tabular}

Figure 2.

Research framework

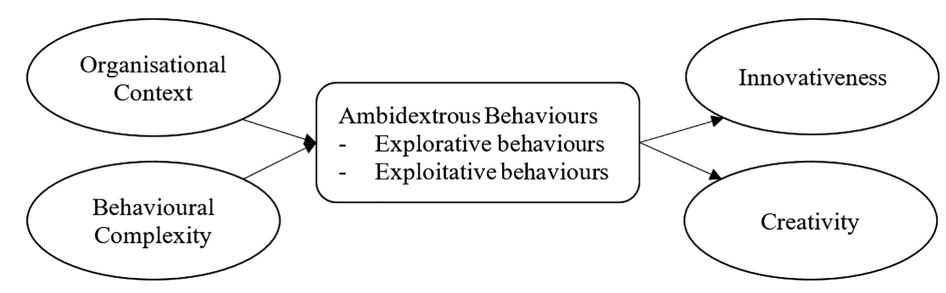

\section{Table VI.}

Standard beta, standard error, $T$ value, variance explained and predictive relevance

\begin{tabular}{|c|c|c|c|c|c|c|c|}
\hline Нyp & Relationships & $\beta$ & Std. Error & $T$-value & Results & $R^{2}$ & $Q^{2}$ \\
\hline 11 & $\mathrm{AB} \rightarrow$ Creativity & 0.473 & 0.052 & $9.151 *$ & Significant & 0.224 & 0.123 \\
\hline $\mathrm{H} 2$ & $\mathrm{AB} \rightarrow$ Innovativeness & 0.375 & 0.057 & $6.566^{*}$ & Significant & 0.141 & 0.089 \\
\hline H3 & $\mathrm{OC} \rightarrow$ Explorative Behaviours & 0.457 & 0.095 & $4.829 *$ & Significant & & \\
\hline $\mathrm{H} 4$ & $\mathrm{OC} \rightarrow$ Exploitative Behaviours & 0.359 & 0.100 & $3.605^{*}$ & Significant & & \\
\hline H5 & $\mathrm{OC} \rightarrow \mathrm{AB}$ & 0.002 & 0.003 & 0.605 & Not Significant & & \\
\hline H6 & $\mathrm{BC} \rightarrow$ Explorative Behaviours & 0.310 & 0.088 & $3.513^{*}$ & Significant & 0.500 & 0.278 \\
\hline H7 & $\mathrm{BC} \rightarrow$ Exploitative Behaviours & 0.355 & 0.107 & $3.324 *$ & Significant & 0.432 & 0.196 \\
\hline $\mathrm{H} 8$ & $\mathrm{BC} \rightarrow \mathrm{AB}$ & 0.001 & 0.003 & 0.159 & Not Significant & & \\
\hline
\end{tabular}

Note(s): ${ }^{*} p<0.01, R^{2}=$ Variance Explained, $Q^{2}=$ Stone-Geisser Predictive Relevance (Bootstrapping $=5,000$, Omission Distance, $D=7$ ) 


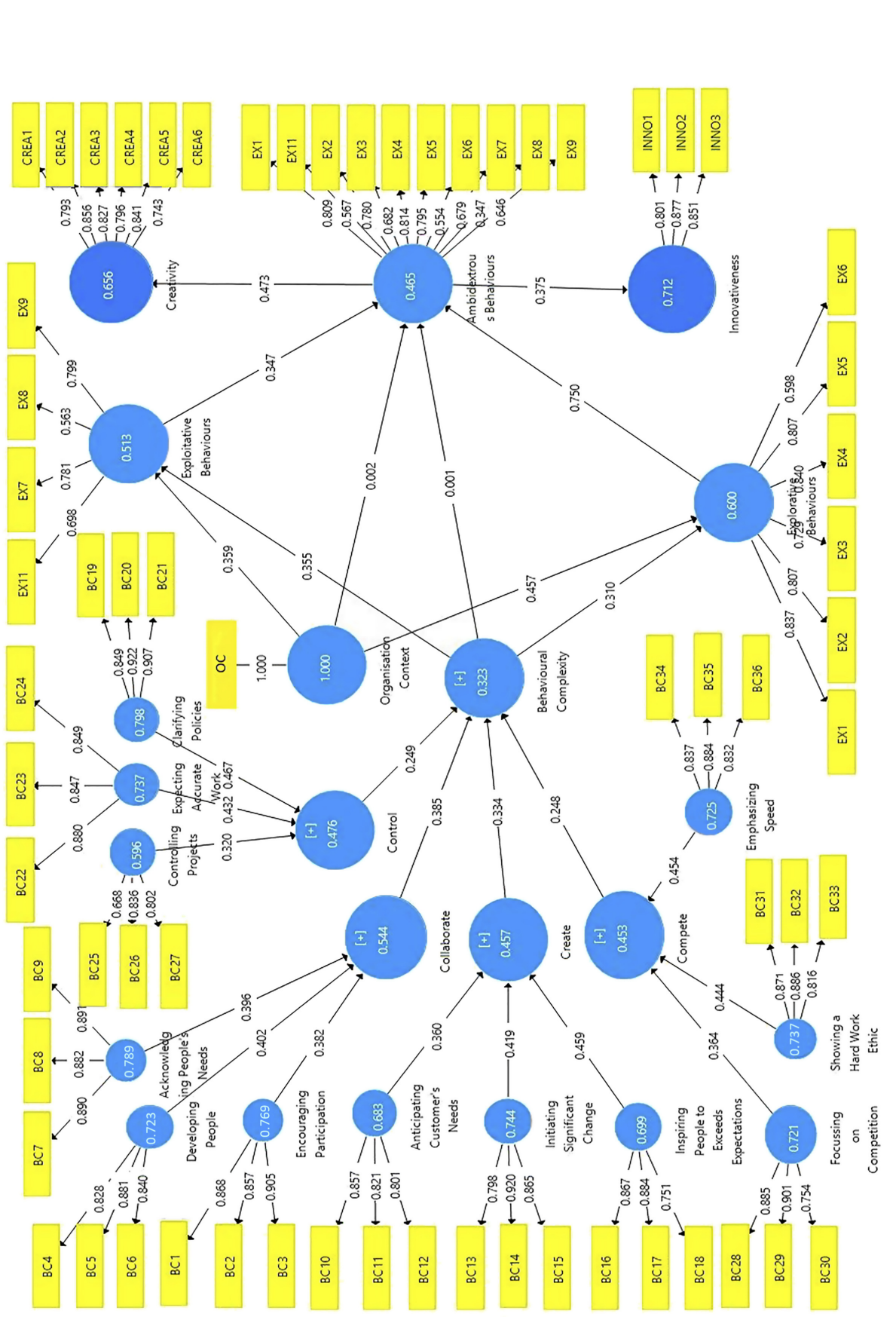

Ambidextrous behaviours among SMEs 


\section{IJOTB}

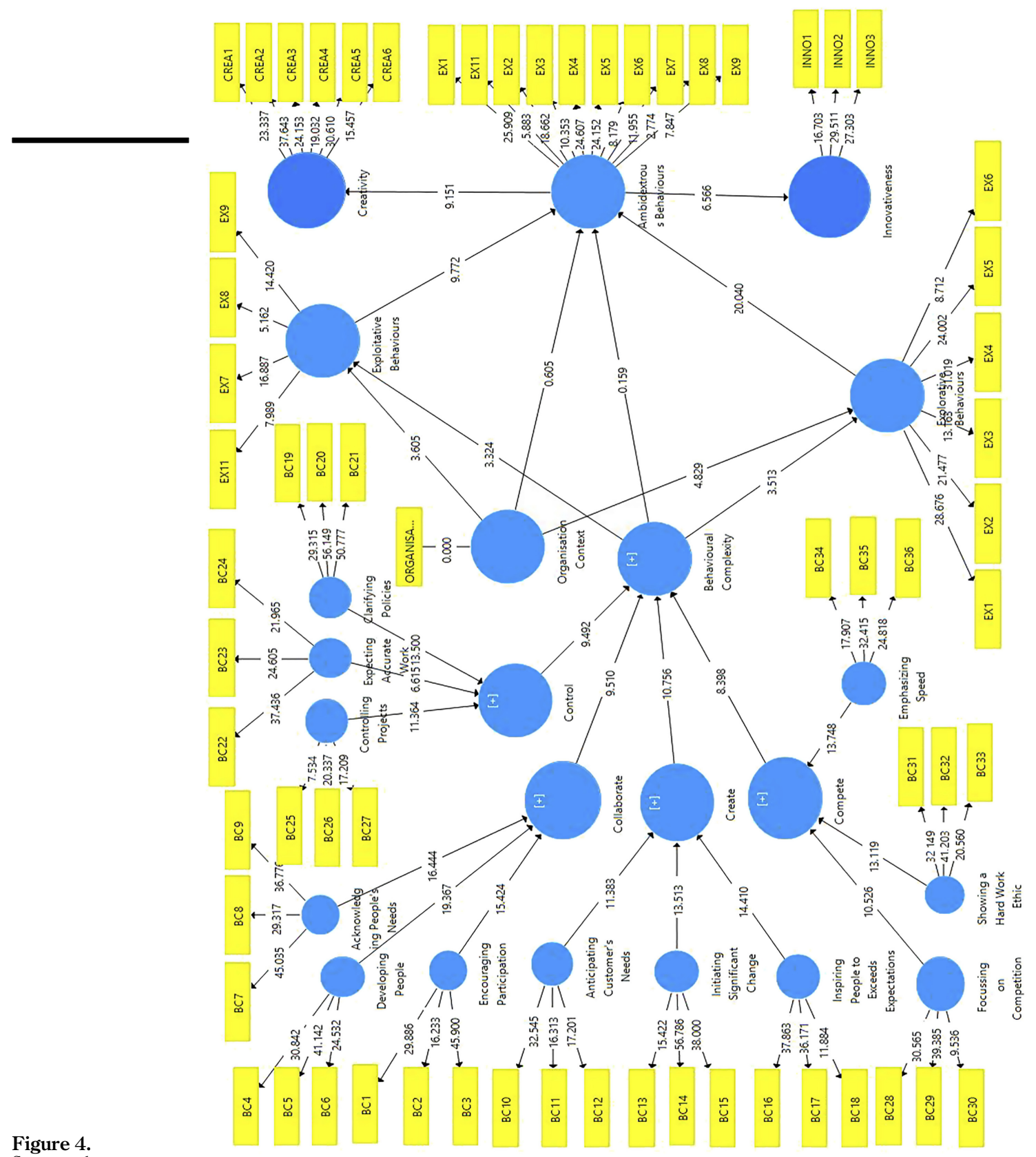


solutions to existing or new issues. Hence, $A B$ cultivates a mind-set encouraging owner-managers to be creative and innovative. Having a creative and innovative mind-set will then emanate throughout the SMEs, thus developing it as a competitive advantage for the firm. Another positive observation is that employees are more likely to suggest, attempt, participate in giving new approaches towards resolving issues where some employees would mimic $\mathrm{AB}$ exhibited by their superiors. While creativity and innovations are riddles with tensions (Lewis et al., 2002), paradoxes (Miron-Spektor et al., 2004), contradictions and dilemmas (Benner and Tushman, 2003), AB acts as an important link in nurturing and facilitating creative and innovative outputs. Therefore, consolidating between explorative and exploitative behaviours increases the ability to foster and balance both contradicting behaviours, allowing owner-managers to engage in the creative and innovative process. These findings are in line with previous studies (Visser and Faems, 2015; Zacher and Rosing, 2015) which reported that ambidexterity significantly influences the innovation and creativity.

The finding revealed that $\mathrm{OC}$ and $\mathrm{BC}$ play an important role in the development of both exploitative and explorative behaviours. Through a supportive OC, it enables and encourages owner-managers to be more willing to engage in both exploitative and explorative behaviours.

Consequently, owner-managers face challenges in continuously seeking new opportunities. Meanwhile, in a social context, support and trust enable a supportive environment that allows individuals to be more willing to engage in explorative behaviours. With the creation of a supportive environment, owner-managers will feel "safe" to venture out and explore new knowledge and opportunities. Through performance management context, the individual is required to be disciplined and stretch. Due to the performance-driven context, individuals are more likely to stretch in achieving challenging goals. On top of that, in an environment where SMEs are relatively small, the relationship between ownermanagers and employees is more tightly knit, and they become more willing and motivated in striving as a one. Individuals would be able to depend on one another's support in completing multiple complex tasks. This strong cohesion within the firm supports the establishment of exploitative and explorative behaviours. This is in contrast to existing larger or older companies which adopt a traditional mechanistic approach (top-down) that does not encourage much teamwork.

Similarly, the findings showed that the relationship of $\mathrm{BC}$ with explorative and exploitative behaviours was positive and statistically significant. This finding is consistent with the belief that it is insufficient for owner-managers to be able to perform different opposing behaviours and they need to switch between behavioural roles to match their environment (Rosing et al., 2011). As BC was modelled as a third-order factor, the present paper argues that ownermanagers must be competent in all four quadrants of $\mathrm{BC}$ to allow them to be responding more effectively to different challenges. The present empirical result suggests that owner-managers need to be like a chameleon that can blend and adapt seamlessly to their environment which might require different behaviours roles (e.g. create, collaborate, compete and control) in the cultivation of exploitative and explorative behaviours. It is important to point out that although the present study views $\mathrm{BC}$ as a factor, owner-managers may not be equally competent in all four quadrants. Instead, owner-managers are able to exhibit each behavioural role to a certain extend. Furthermore, $\mathrm{BC}$ orients owner-managers to position themselves more effectively in challenging environments.

Unexpectedly, this study found that $\mathrm{OC}$ and $\mathrm{BC}$ do not significantly influence $\mathrm{AB}$. While only by exhibiting both exploitative and explorative behaviours, owner-managers are considered to be ambidextrous. The findings suggest that $\mathrm{OC}$ and $\mathrm{BC}$ significantly impact explorative and exploitative behaviours, as it falls upon the owner-managers' ability reconcile such contradicting behaviours to be ambidextrous. The main challenge of enabling $\mathrm{AB}$ is the capacity to maintain explorative behaviours alongside exploitative behaviours (Lavie, 2010). Thus, AB must be backed with sufficient effort in exploitative and explorative
Ambidextrous behaviours among SMEs 
behaviours. The present empirical results suggest that being ambidextrous relies upon an individual's ability to host multiple contradictions. $\mathrm{OC}$ and $\mathrm{BC}$ play an important role in cultivating explorative and exploitative behaviours. However, an individual's cognitive capability is necessary to achieve the optimum balance between explorative and exploitative behaviours to be ambidextrous. One may be more inclined to over-invest in exploitative behaviour due to its certainty as compared to explorative behaviour, which does not have an immediate result. Specifically, the findings imply that individual's willingness coupled with organisational support enables AB. This finding is consistent with previous studies (Kauppila and Tempelaar, 2016) which suggested that to understand ambidexterity, individual characteristics, capability and behaviours must be taken into account to present a holistic view for $\mathrm{AB}$.

\section{Limitation and future research}

This research is not without its limitations. These limitations could provide avenues for future research. The first limitation is that as the responses were gathered from the perspective of the owner-managers, one should be aware of their potential bias. For example, the respondents might over-estimate their ability and skill when self-reporting their perception towards creativity and innovativeness. To overcome this limitation, future research could consider dyadic data and a detailed analysis of innovative performance by the SMEs. The findings of this study show that $\mathrm{OC}$ and $\mathrm{BC}$ can lead to exploitative and explorative behaviours, but not $\mathrm{AB}$. An important extension of ambidextrous research would be to examine the types of antecedents influencing exploitative and explorative behaviours as compared to current emphasis of AB only (Poon et al., 2018a; Junni et al., 2013). Identifying the crucial factors that encourage exploitative or explorative behaviours would enrich the current understanding of the ambidextrous theory. Furthermore, the present research examined $\mathrm{OC}$ and $\mathrm{BC}$ influencing exploitative and explorative behaviours, future research may examine the existing list of antecedents for $\mathrm{AB}$ and their roles affecting exploitative and explorative behaviours, such as leadership, human resource management and intrinsic factors. For owner-managers to be ambidextrous demands substantial cognitive and psychological efforts on the individual, as well as adequate external support. Hence, specific behaviour or strategy facilitates the formation of exploitative and explorative behaviours, ultimately enabling owner-managers to be ambidextrous.

\section{Conclusion}

In conclusion, there is no doubt that $\mathrm{AB}$ generates competitive advantages for an organisation. This study provides a glimpse to owner-managers to formulate a suitable OC and $\mathrm{BC}$ to promote exploitative and explorative behaviours. By carefully delineating the effect of $\mathrm{OC}$ and $\mathrm{BC}$ on exploitative and explorative behaviours, researcher and managers can focus on encouraging specific behaviours and environment to cultivate relevant behaviours to be ambidextrous. By being ambidextrous, SMEs can adequately prepare to face innovation cycles and contradictory demands due to the changes in the internal or external business environment. Through AB, SMEs can carefully build a collective effort looking beyond short-term returns by seeking opportunities that safeguard long-term growth and prosperity.

\section{References}

Adler, P.S., Goldoftas, B. and Levine, D.I. (1999), "Flexibility versus efficiency: a case study of model changeovers in the toyota production system", Organization Science, Vol. 10 No. 1, pp. $43-68$. 
Amabile, T.M. (2013), "Componential theory of creativity", in Kessler, E.H. (Ed.), Encyclopedia of Management Theory, SAGE Publications, London, pp. 134-139.

Arham, A.F. (2014), The Relationship between Leadership Behavior, Entrepreneurial Orientation and Organizational Performance in Malaysian Small and Medium Enterprises, Royal Melbourne Institute of Technology University, Australia.

Baer, M. (2012), "Putting creativity to work: the implementation of creative ideas in organizations", Academy of Management Journal, Vol. 55 No. 5, pp. 1102-1119.

Benner, M.J. and Tushman, M.L. (2003), "Exploitation, exploration, and process management: the productivity dilemma revisited", Academy of Management Review, Vol. 28 No. 2, pp. 238-256.

Coakes, E., Amar, A. and Luisa Granados, M. (2010), "Knowledge management, strategy, and technology: a global snapshot”, Journal of Enterprise Information Management, Vol. 23 No. 3, pp. 282-304, doi: 10.1108/17410391011036076.

Covin, J.G. and Slevin, D.P. (1989), "Strategic management of small firms in hostile and benign environments", Strategic Management Journal, Vol. 10 No. 1, pp. 75-87.

Denison, D.R., Hooijberg, R. and Quinn, R.E. (1995), "Toward a theory of behavioral complexity in managerial leadership", Organization Science, Vol. 6 No. 5, pp. 524-540.

Drucker, P. (2014), Innovation and Entrepreneurship, Routledge, New York.

Farjoun, M. (2010), "Beyond dualism: stability and change as a duality", Academy of Management Review, Vol. 35 No. 2, pp. 202-225.

Faul, F., Erdfelder, E., Lang, A.G., Buchner, A. and Kiel, C. (2007), "G*Power3: a flexible statistical power analysis program for the social, behavioral, and biomedical sciences", Behavior Research Methods, Vol. 39 No. 2, pp. 175-191.

Gerbing, D.W. and Anderson, J.C. (1988), "An updated paradigm for scale development incorporating unidimensionality and its assessment", Journal of Marketing Research, Vol. 25, pp. 186-192.

Ghoshal, S. and Bartlett, C.a. (1994), "Linking organizational context and managerial action: the dimensions of quality of management", Strategic Management Journal, Vol. 15, pp. 91-112.

Gibson, C.B. and Birkinshaw, J. (2004), "The antecedents, consequences, and mediating Role of organizational ambidexterity", Academy of Management Journal, Vol. 47 No. 2, pp. 209-226.

Griffin, M.A., Parker, S.K. and Neil, A. (2007), "A new model of work role performance: positive behavior in uncertain and interdependent contexts", Academy of Management Journal, Vol. 50 No. 2, pp. 327-347.

Gupta, R. and Sebastian, V.J. (2017), "Configuration approach to strategic and entrepreneurial orientation construct and small firm growth: evidence from India", Theoretical Economics Letters, Vol. 07 No. 5, pp. 1261-1281.

Gupta, A.K., Smith, K.G. and Shalley, C.E. (2006), "The interplay between exploration and exploitation", Academy of Management Journal, Vol. 49 No. 4, pp. 693-706.

Hair, J.F., Hult, G.T.M., Ringle, C.M. and Sarstedt, M. (2017), A Primer on Partial Least Squares Structural Equation Modeling (PLS-SEM), 2nd ed., Sage, Thousand Oaks, CA.

Hazlina Ahmad, N., Ramayah, T., Wilson, C. and Kummerow, L. (2010), "Is entrepreneurial competency and business success relationship contingent upon business environment?", International Journal of Entrepreneurial Behaviour and Research, Vol. 16 No. 3, pp. 182-203.

Heavey, C., Simsek, Z. and Fox, B.Curtis. (2015), "Managerial social networks and ambidexterity of SMEs: the moderating role of a proactive commitment to innovation", Human Resource Management, Vol. 45 No. 3, pp. 1-21.

Henseler, J. and Fassott, G. (2010), "Testing moderating effects in PLS path models: an illustration of available procedures", in Esposito Vinzi, V., Chin, W., Henseler, J. and Wang, H. (Eds), Handbook of Partial Least Squares. Springer Handbooks of Computational Statistics, Springer, Berlin, Heidelberg, pp. 713-735.
Ambidextrous behaviours among SMEs 
Hooijberg, R. and Quinn, R.E. (1992), "Behavioral complexity and the development of effective managers", in Phillips, R.L. and Hunt, J.G. (Eds), Strategic Leadership: A MultiorganizationalLevel Perspective, Quorum Books, Greenwood Publishing Group, Westport, CT, pp. 161-175.

Hooijberg, R., (Jerry) Hunt, J.G. and Dodge, G.E. (1997), "Leadership complexity and development of the leaderplex model", Journal of Management, Vol. 23 No. 3, pp. 375-408, doi: 10.1177/ 014920639702300305.

Ilies, R., Morgeson, F.P. and Nahrgang, J.D. (2005), "Authentic leadership and eudaemonic well-being: understanding leader-follower outcomes", The Leadership Quarterly, Vol. 16 No. 3, pp. 373-394.

Jansen, J.J.P., George, G., Van Den Bosch, F.A.J. and Volberda, H.W. (2008), "Senior team attributes and organizational ambidexterity: the moderating role of transformational leadership", Journal of Management Studies, Vol. 45 No. 5, pp. 982-1007.

Jia, L., Shaw, J.D., Tsui, A.S. and Park, T.Y. (2014), "A social-structural perspective on employeeorganization relationships and team creativity", Academy of Management Journal, Vol. 57 No. 3 , pp. 869-891.

Junni, P., Sarala, R.M., Taras, V. and Tarba, S.Y. (2013), "Organizational ambidexterity and performance: a meta-analysis", Academy of Management Perspectives, Vol. 27 No. 4, pp. 299-312.

Kauppila, O.P. and Tempelaar, M.P. (2016), “The social-cognitive underpinnings of employees' ambidextrous behavior and the supportive role of group managers' leadership", Journal of Management Studies, Vol. 53 No. 6, pp. 1019-1044.

Kline, R.B. (2005), Principles and Practices of Structural Equation Modeling, 2nd Ed., Guilford Press, New York.

Knight, G.A. and Cavusgil, S.T. (2004), "Innovation organizational capabilities and the born-global firm”, Journal of International Business Studies, Vol. 35 No. 2, pp. 124-141.

Lane, P.J. and Lubatkin, M. (1998), "Relative absorptive capacity and interorganizational learning", Strategic Management Journal, Vol. 19 No. 5, pp. 461-477.

Lavie, D., Stettner, U. and Tushman, M.L. (2010), "Exploration and exploitation within and across organizations", The Academy of Management Annals, Vol. 4 No. 1, pp. 109-155.

Lawrence, K.a., Lenk, P. and Quinn, R.E. (2009), "Behavioral complexity in leadership: the psychometric properties of a new instrument to measure behavioral repertoire", The Leadership Quarterly, Elsevier, Vol. 20 No. 2, pp. 87-102.

Lewis, M.W., Welsh, M.A., Dehler, G.E. and Green, S.G. (2002), "Product development tensions exploring contrasting styles of project management", Academy of Management Journal, Vol. 45 No. 3, pp. 546-564.

Lubatkin, M.H., Simsek, Z., Ling, Y. and Veiga, J.F. (2006), "Ambidexterity and performance in smallto medium-sized firms: the pivotal role of top management team behavioral integration", Journal of Management, Vol. 32 No. 5, pp. 646-672.

March, J.G. (1991), "Exploration and exploitation in organizational learning”, Organization Science, Vol. 2 No. 1, pp. 71-87.

Miron-Spektor, E., Gino, F. and Argote, L. (2011), "Paradoxical frames and creative sparks: enhancing individual creativity through conflict and integration", Organizational Behavior and Human Decision Processes, Elsevier, Vol. 116 No. 2, pp. 229-240.

Mom, T.J.M., Van Den Bosch, Frans A.J. and Volberda, H.W. (2009), "Understanding variation in managers' ambidexterity: investigating direct and interaction effects of formal structural and personal coordination mechanisms", Organization Science, Vol. 20 No. 4, pp. 812-828.

O'Reilly, C.A. and Tushman, M.L. (2013), "Organizational ambidexterity: past, present and future", Academy of Management Perspectives, Vol. 27 No. 4, pp. 324-338.

Podsakoff, P.M. and Organ, D.W. (1986), "Self-reports in organizational research: problems and prospects”, Journal of Management, Vol. 12 No. 4, pp. 531-544. doi: 10.1177/014920638601200408. 
Poon, W.C., Mohamad, O. and Yusoff, W.F.W. (2018a), "The impact of behavioural complexity on exploitative and explorative behaviour among owner-managers of SMEs in Malaysia", Academy of Strategic Management Journal, Vol. 17 No. 1, pp. 1-13.

Poon, W.C., Mohamad, O. and Yusoff, W.F.W. (2018b), "Examining the antecedents of ambidextrous behaviours in promoting creativity among SMEs in Malaysia", Global Business Review, Vol. 21 No. 3, pp. 1-18.

Popadić, M. and Černe, M. (2016), "Exploratory and exploitative innovation: the moderating role of partner geographic diversity", Economic Research-Ekonomska Istra?Ivanja, Routledge, Vol. 29 No. 1, pp. 1165-1181.

Quinn, R.E. and Rohrbaugh, J. (1983), "A spatial model of effectiveness criteria: towards a competing values approach to organizational analysis", Management Science, Vol. 29 No. 3, pp. 363-377.

Raisch, S., Birkinshaw, J., Probst, G. and Tushman, M.L. (2009), "Organizational ambidexterity: balancing exploitation and exploration for sustained performance", Organization Science, Vol. 20 No. 4, pp. 685-695.

Rauch, A., Wiklund, J., Lumpkin, G.T. and Frese, M. (2009), "Entrepreneurial orientation and business performance: an assessment of past research and suggestions for the future", Entrepreneurship: Theory and Practice, Vol. 33 No. 3, pp. 761-787.

Rosing, K., Frese, M. and Bausch, A. (2011), "Explaining the heterogeneity of the leadershipinnovation relationship: ambidextrous leadership", The Leadership Quarterly, Elsevier, Vol. 22 No. 5, pp. 956-974.

Sarooghi, H., Libaers, D. and Burkemper, A. (2015), "Examining the relationship between creativity and innovation: a meta-analysis of organizational, cultural, and environmental factors", Journal of Business Venturing, Elsevier, Vol. 30 No. 5, pp. 714-731.

Shane, S. (2000), "Prior knowledge and the discovery of entrepreneurial opportunities", Organization Science, Vol. 11 No. 4, pp. 448-469.

Simsek, Z., Heavey, C., Veiga, J.F. and Souder, D. (2009), "A typology for aligning organizational ambidexterity's conceptualizations, antecedents, and outcomes", Journal of Management Studies, Vol. 46 No. 5, pp. 864-894.

SME Corporation Malaysia (2012), SME Masterplan 2012-2020: Innovation-Led and ProductivityDriven Growth, SME Corp. Malaysia, Malaysia, available at: http://www.smeinfo.com.my/ policy-regulation/sme-masterplan (accessed 2 December 2018).

SME Corporation Malaysia (2016), SME Are the Backbone of the Economy, SME Corp, Malaysia, available at: https:/www.smecorp.gov.my/index.php/en/policies/2015-12-21-09-09-49/sme-statistics (accessed 2 December 2018).

Smith, W.K., Besharov, M.L., Wessels, A.K. and Chertok, M. (2012), “A paradoxical leadership model for social entrepreneurs: challenges, leadership skills, and pedagogical tools for managing social and commercial demands", The Academy of Management Learning and Education, Vol. 11 No. 3, pp. 463-478.

Tushman, M.L. and O'Reilly, C.A. (1996), “Ambidextrous organizations: managing evolutionary and revolutionary change", California Management Review, Vol. 38 No. 4, pp. 8-30.

Visser, M. and Faems, D. (2015), "Exploration and exploitation within firms: the impact of CEOs' cognitive style on incremental and radical innovation performance", Creativity and Innovation Management, Vol. 24 No. 3, pp. 359-372.

Voorhees, C.M., Brady, M.K., Calantone, R. and Ramirez, E. (2016), "Discriminant validity testing in marketing: an analysis, causes for concern, and proposed remedies", Journal of the Academy of Marketing Science, Vol. 44 No. 1, pp. 119-134.

Voss, G.B. and Voss, Z.G. (2013), "Strategic ambidexterity in small and medium-sized product and market domains strategic ambidexterity in small and medium-sized enterprises: implementing exploration and exploitation in product and market domains", Organization Science, Vol. 24 No. 5, pp. 1459-1477. 
Weick, K.E. (2003), "Positive organizing and organizational tragedy", in Cameron, K.S., Dutton, J.E. and Quinn, R.E. (Eds), Positive Organizational Scholarship: Foundations of a New Discipline, Berrett-Koehler, San Francisco, pp. 66-80.

Wright, P.M. and Snell, S.A. (1998), "Toward a unifying framework for exploring fit and flexibility in strategic human resource management", Academy of Management Review, Vol. 23 No. 4, pp. 756-772.

Zacher, H. and Rosing, K. (2015), “Ambidextrous leadership and team innovation”, The Leadership and Organization Development Journal, Vol. 36 No. 1, pp. 1-29.

\section{Appendix}

\section{Measurement items}

Organisational context (OC) (Ghoshal and Bartlett, 1994)

To what extent to which systems encouraged me to...

\section{Performance management context}

(1) Set challenging/aggressive goals.

(2) Issue creative challenges to the people, instead of narrowly defining tasks.

(3) Be more focused on getting their job done well than on getting promoted.

(4) Make a point of stretching people.

(5) Reward or punish based on strict measurement of business performance against goals.

(6) Hold people accountable for their performance.

(7) Use their appraisal feedback to improve their performance.

\section{Social context}

(1) Devote considerable effort to developing their employees.

(2) Give everyone sufficient authority to do their jobs well.

(3) Push decisions down to the lowest appropriate level.

(4) Give ready-access information that others need.

(5) Work hard to develop the capabilities needed to execute our overall strategy/vision.

(6) Base decisions on facts and analysis, not politics.

(7) Treat failure (in a good effort) as a learning opportunity, not something to be ashamed of.

(8) Are willing and able to take prudent risks.

(9) Set realistic goals.

Behavioural complexity (BC) (Lawrence et al., 2009)

I would describe myself as being skilled in the following. . .

\section{Collaborate}

(1) Making it a rule to contribute opinions.

(2) Employing participative decision-making.

(3) Maintaining an open concept for discussion.

(4) Encourage for career development.

(5) Seeing that everyone has a career development plan. 
(6) Guiding people on career issues.

(7) Being aware of when people are burning out.

(8) Encouraging people to have work/life balance.

(9) Recognising feelings.

\section{Create}

(1) Meeting with customers to discuss their needs.

(2) Identifying the changing needs of the customer.

(3) Anticipating what the customer will want next.

(4) Initiating daring projects.

(5) Starting ambitious programmes.

(6) Launching important new efforts.

(7) Inspiring colleagues to be creative.

(8) Encouraging colleagues to try new things.

(9) Getting colleagues to exceed traditional performance patterns.

\section{Control}

(1) Seeing that corporate policies are understood.

(2) Ensuring that company policies are known.

(3) Making sure formal guidelines are clear to people.

(4) Emphasising the need for accuracy in work efforts.

(5) Expecting people to get the details of their work right.

(6) Emphasising accuracy in work efforts.

(7) Providing tight project management.

(8) Keeping projects under control.

(9) Closely managing projects.

\section{Compete}

(1) Emphasising the need to compete.

(2) Developing a competitive focus.

(3) Insisting on beating outside competitors.

(4) Showing an appetite for hard work.

(5) Modelling an intense work effort.

(6) Demonstrating full effort on the job.

(7) Getting work done quicker in the unit.

(8) Producing faster unit outcomes.

(9) Providing fast responses to emerging issues. 


\section{Explorative behaviours}

(1) Looks for novel ideas by thinking "out the box."

(2) Bases success on its ability to explore new technologies.

(3) Creates products or services that are innovative to the firm.

(4) Looks for creative ways to satisfy customer's needs.

(5) Aggressively ventures into new market segments.

(6) Actively targets new customer groups.

\section{Exploitative behaviours}

(1) Commits to improve quality and lower cost.

(2) Continuously improves the reliability of products and services.

(3) Increases the level of automation in our operation.

(4) Constantly surveys existing customers' satisfaction.

(5) Fine-tunes what is offered to keep its current customers satisfied.

(6) Penetrates more deeply into existing customer base.

Creativity (Jia et al., 2014)

(1) I seek new ideas and ways to solve problems.

(2) I try new ideas or methods first.

(3) I generate ground-breaking ideas related to the field.

(4) I am a good role model for creativity.

(5) I generate new processes.

(6) I generate new inventions.

Innovativeness (Covin and Slevin, 1989)

(1) In the past five years, we made huge changes in product or service line.

(2) In the past five years, we produced many new products and services.

(3) A strong emphasis on R\&D, technology, leadership and innovation.

\section{Corresponding author}

Wai Chuen Poon can be contacted at: eugenepoon86@gmail.com

For instructions on how to order reprints of this article, please visit our website: www.emeraldgrouppublishing.com/licensing/reprints.htm Or contact us for further details: permissions@emeraldinsight.com 